\title{
Relative secular variations of the geomagnetic field along the Zgorzelec-Wiżajny profile, Poland
}

\author{
Anna Wojas $^{1,}{ }^{*}$, Teresa Grabowska ${ }^{1}$, and Mateusz Mikołajczak ${ }^{2}$ \\ ${ }^{1}$ AGH University of Science and Technology, Faculty of Geology, Geophysics and Environmental \\ Protection, al. Mickiewicza 30, 30-059 Krakow, Poland \\ ${ }^{2}$ Polish Academy of Sciences, Institute of Geological Sciences, Krakow Research Centre, Senacka 1, \\ 31-002 Krakow, Poland
}

\begin{abstract}
The paper presents results of the study on relative secular variations of total magnetic intensity (TMI) of the geomagnetic field along the $700 \mathrm{~km}$ long profile crossing the area of Poland. Surveys were carried out at annual intervals between 1966 and 2016 (50 measurement series), in 31 survey sites (secular points) separated by about $22 \mathrm{~km}$. The studied profile of the SW-NE direction, called Zgorzelec-Wiżajny (Z-W), crosses large parts of the main tectonic units of Europe, namely the Palaeozoic Platform of Central and Western Europe (PLZ) and the East European Craton (EEC), connected by the Teisseyre-Tornquist Zone (TTZ). Using the original methodology of analysis of measured data, reduced to the values of geomagnetic field recorded at the Central Geophysical Observatory in Belsk, the relative secular variations of TMI with the magnetic anomalies $(\Delta T)$ and the terrestrial heat flow density $(Q)$ were graphically presented. Key words - relative secular variations, geomagnetic field, Palaeozoic Platform, Teisseyre-Tornquist Zone, East European Craton.
\end{abstract}

\section{Introduction}

The first map of secular variations of the geomagnetic field in Poland has been presented by Kalinowski at the Congress of the Geodetic-Geophysical Union in Stockholm in 1930. The first scientific papers dealing with this issue were published in 1936, in the Geophysical Society Bulletin. After the Second World War, in 1952, Olczak presented a paper in the PIG Bulletin about secular variations of the Earth's magnetic field (D, I, H, Z) in the period of time 1900-1950. Since 1957, the Institute of Geodesy and Cartography in Warsaw has been carried out surveys of the geomagnetic field at 20 stabilized secular points (repeat stations) in Poland $[1,2]$. The results with comments were compiled in the form of tables and maps (D, H, T) representing 20 year period (1970-1990) [3]. An important summary of these studies is provided in a paper by Welker and Zoltowski [4], presenting the normal field of secular variations of the geomagnetic field for the Polish territory. It is also worth to mention a paper by Welker [5] that presents changes in the geomagnetic field $(\mathrm{D}, \mathrm{T})$ in the last

\footnotetext{
* Corresponding author: awojas@agh.edu.pl
} 
quarter of the century in Central Europe. The author emphasized the necessity of systematic measurements of the geomagnetic field in secular points.

The studies of secular changes, presented in this paper, were initiated in the 1960 s by Maloszewski [6] and have been continued until present (1966-2016). The geomagnetic field surveys are performed along the $700 \mathrm{~km}$ profile Zgorzelec-Wiżajny (Z-W) (Fig. 1). The profile runs across fragments of two main European tectonic units, namely the Palaeozoic Platform of Central and Western Europe (PLZ) and the East European Craton (EEC) connected by the Teisseyre-Tornquist Zone (TTZ). The aim of the study is to determine the local relative secular variations of TMI and attempt to assess their causes [7].

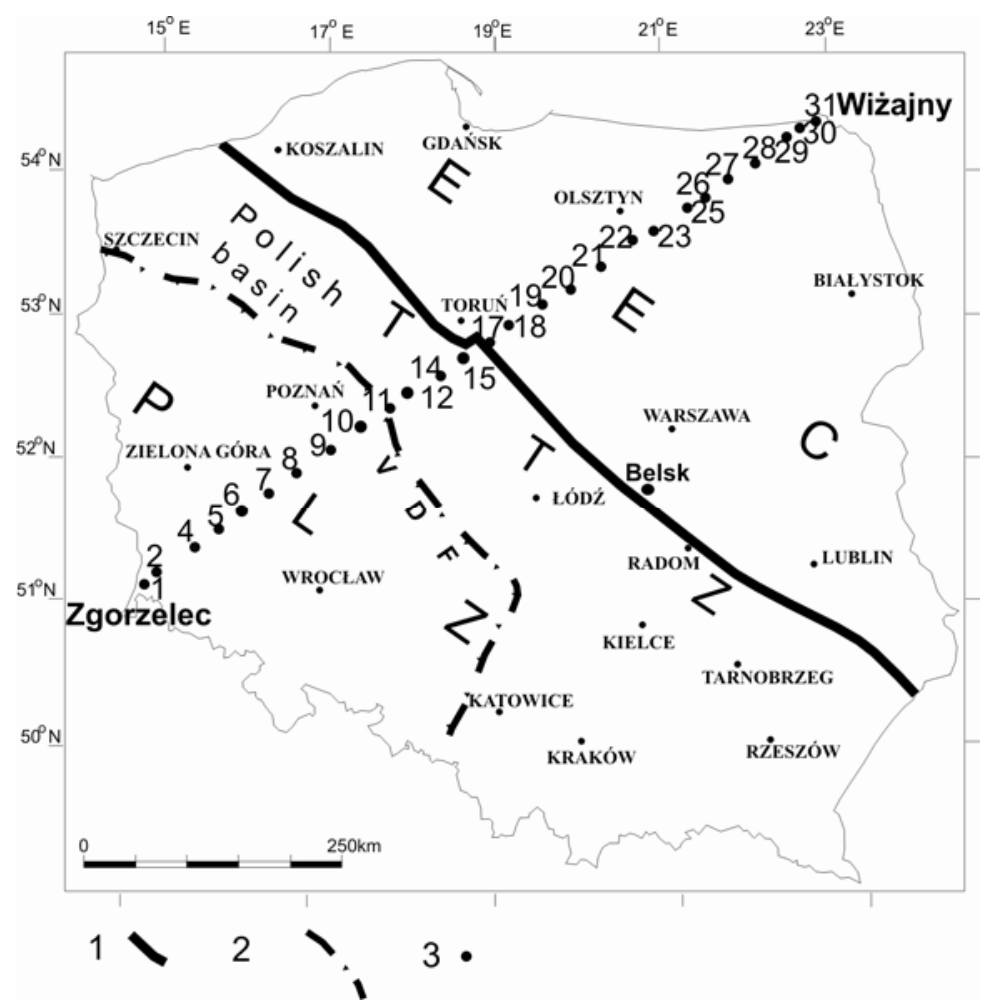

Fig. 1. Location of secular points along the Zgorzelec-Wiżajny (Z-W) profile. Explanation: 1 - Teisseyre-Tornquist Zone (TTZ) according to deep seismic surveys [8], 2 - Variscan Deformation Front (VDF) [9], 3 - secular points. Other abbreviations: EEC - the East European Craton, PLZ - the Palaeozoic Platform of Central and Western Europe

\section{Methodology of survey and results processing}

Annual surveys of TMI of the geomagnetic field were made in 31 GPS-determined points along the $\mathrm{Z}-\mathrm{W}$ profile. Magnetic measurements were conducted with the use of proton magnetometers with $0.1 n T$ sensitivity. In total, 50 measurement series of TMI have been accomplished in the years 1966-2016. A series of measurements has been made at each point, called a secular point (approximately 60 records with 1 minute repetition) in order to validate the TMI value. After that, the TMI values in each secular point $(n)$ were reduced to the values of the TMI recorded at the same time at the Central Geophysical Observatory in Belsk (formula 1). The definitive value of relative secular variation $\left(\Delta T_{n, t}\right)$ in a secular point $(n)$ in the year $(t)$ is an average value of reduction results. 


$$
\Delta T_{n, t}=\frac{1}{60} \sum_{1}^{60}\left|\vec{T}_{o b s, n,(\tau+\Delta \tau)}\right|-\left|\vec{T}_{B e l s k, \tau}\right|
$$

where:

$\tau$ - time of measurement in GMT (Greenwich Mean Time),

$\Delta \tau$ - time correction related to the difference in longitude between measurement point and the Belsk Observatory.

Methodology of the TMI relative variations determination and presentation along the Z-W profile was published by Maloszewski and Jankowski [10] and it is used as such until present. On this basis, the values of $\Delta T_{n, t}$ in each secular point in the 50 -years time period (1966-2016) were approximated by the first-order polynomials (formula 2) and graphically illustrated by straight lines, expressing so-called trends of relative secular variations in each secular point within 50 years (Fig. 2). The next stage was graphical illustration of slope coefficient (formula 3).

$$
\begin{gathered}
W_{n}(t)=b_{n} t+a_{n} \\
b_{n}=\partial\left(\Delta T_{n, t}\right)
\end{gathered}
$$

where:

$b_{n}$ - slope coefficient, which corresponds to the relative secular variation of the annual geomagnetic field in an individual secular point of the profile,

$a_{n}$ - mean value of relative values of the geomagnetic field in a secular point, in relation to the mean value of the geomagnetic field measured in the Belsk Observatory, during 50 years of study.

It should be mentioned that studies of relative changes of the geomagnetic field were limited to the territory of Poland and can be treated as local.

The relative secular variations shown in this paper were analysed considering the geological structure of Poland, as well as the observed magnetic anomalies $(\Delta T)$ and values of terrestrial heat flow density $(Q)$ along the Z-W profile.

\section{Magnetic anomalies along the Z-W profile against the geological setting}

The magnetic anomalies $(\Delta T)$ pattern along the $\mathrm{Z}-\mathrm{W}$ profile is characteristic of the central part of the Polish Lowlands. The middle part of the profile (11-17 secular points) (Fig. 1) crosses the Permian-Mesozoic Polish Basin. In its axial part (the Mid-Polish Trough), PermianMesozoic sediments were deposited with a thickness of up to 8 kilometres [11]. According to deep seismic surveys [12], the thickness of the entire Phanerozoic sedimentary complex in this area reaches $12-13 \mathrm{~km}$. The middle part of the profile corresponds to low (negative) values of magnetic anomalies (magnetic low, Fig. 3b), that terminates from the NE against a zone of strong horizontal magnetic gradient coinciding with the TTZ and dividing Poland into two magnetic provinces.

The SW part of the Z-W profile crosses the Fore-Sudetic Monocline (section of the PLZ), where the depth to the pre-Permian basement is c. $1-4 \mathrm{~km}$. In this area, a weak positive magnetic anomalies zone is present, which is probably related to Variscan metamorphic basement occurring at a depth of c. 3-6 km [13]. 


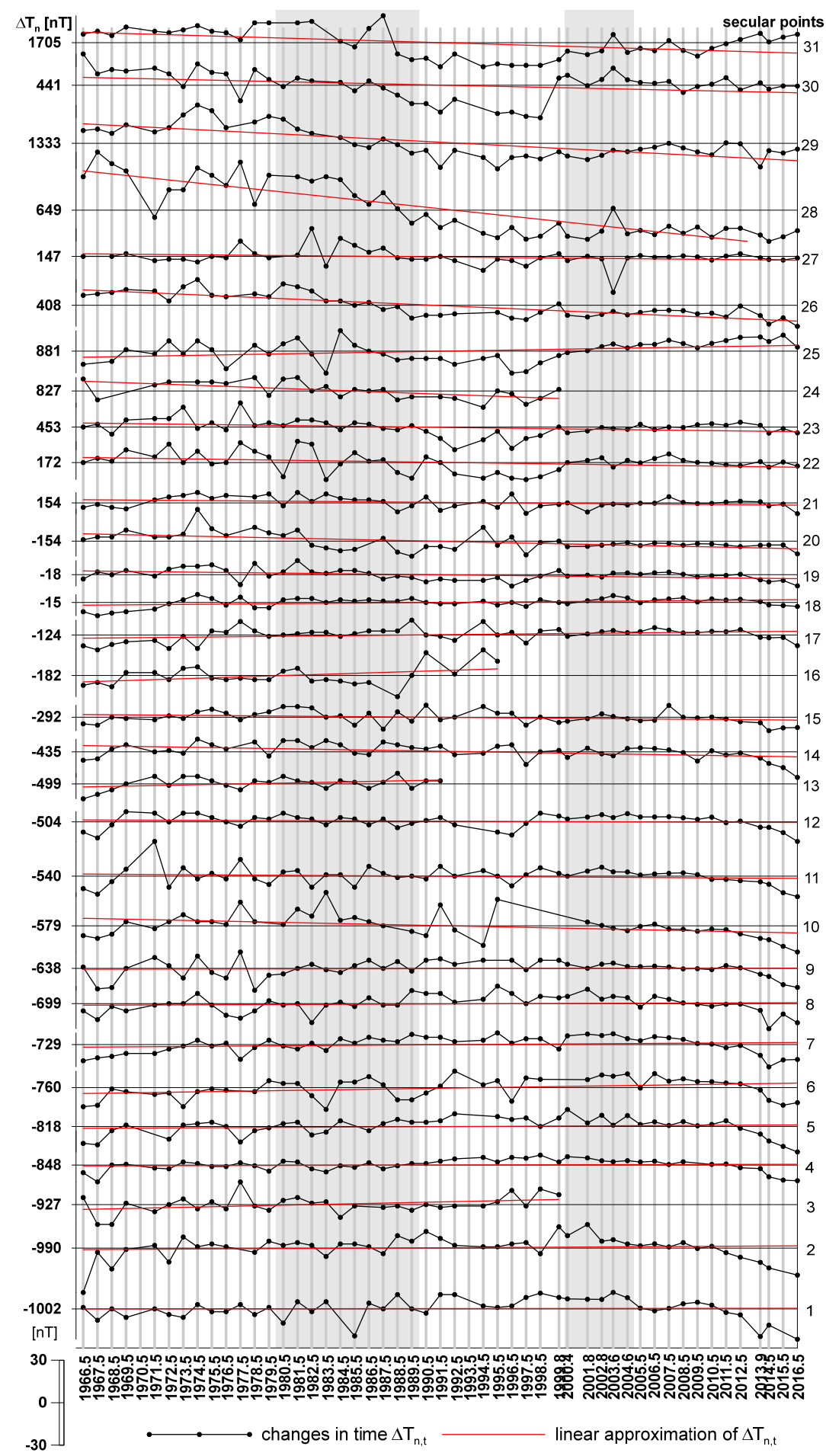

Fig. 2. Changes in time of the relative geomagnetic field values $\Delta T n, t$ in individual secular points of the Zgorzelec-Wiżajny (Z-W) profile. Explanation: $\Delta T n$ - mean values of $\Delta T_{n, t}$ in the period 19662016 for individual secular points, grey background - periods of time (1980-1990 and 2000-2005), when systematic changes of total magnetic intensity (TMI) in Central Europe have been observed [5] 
The magnetic anomalies in the NE section of the Z-W profile reflect the geological structure of the Polish section of the EEC. The profile runs over the Dobrzyń granitoid massif, next to the Ciechanów fold zone, and its Warmia branch, which are under the cover of sedimentary rocks with NE-ward decreasing thickness $(8-1 \mathrm{~km})$. The metamorphic rocks in these zones are source of numerous magnetic anomalies with amplitudes in the order of hundreds of $n T$. The NE termination of the profile is located in the area with strong (over $1000 n T$ ) magnetic anomalies associated with the Mazury complex of rapakivi-like granitoids and the Suwałki anorthosite massif with the iron ores.

\section{Results}

Figure 2 shows the relative secular geomagnetic variations in individual secular points (1-31) of the Z-W profile in the years 1966-2016. On a vertical axis on the left side of the graph, the mean values of changes $(\Delta T n)$ for each point are given using the same scale. From the point 21 (Ciechanów zone, EEC) to the end of the Z-W profile, the $\Delta T n$ values are positive, in other words the geomagnetic field recorded in this area is stronger than in the Belsk Observatory.

Attention should be paid to the areas with the most rapid changes of the TMI secular variations. The amplitudes of changes are over $40.0 n T$ at those sites. The largest changes of the geomagnetic field are in the region of the EEC (secular point no 27, 28, 29, 30, Fig. 2) with a maximum amplitude of $\Delta T_{n, t}$ in the years 1966-2016 (61.5 nT) being observed in the secular point 28 (Mazury complex). Significant amplitudes of the field changes were also observed in the secular points 2 and 10, located in the PLZ area (49.0 nT and $42.8 n T$, respectively).
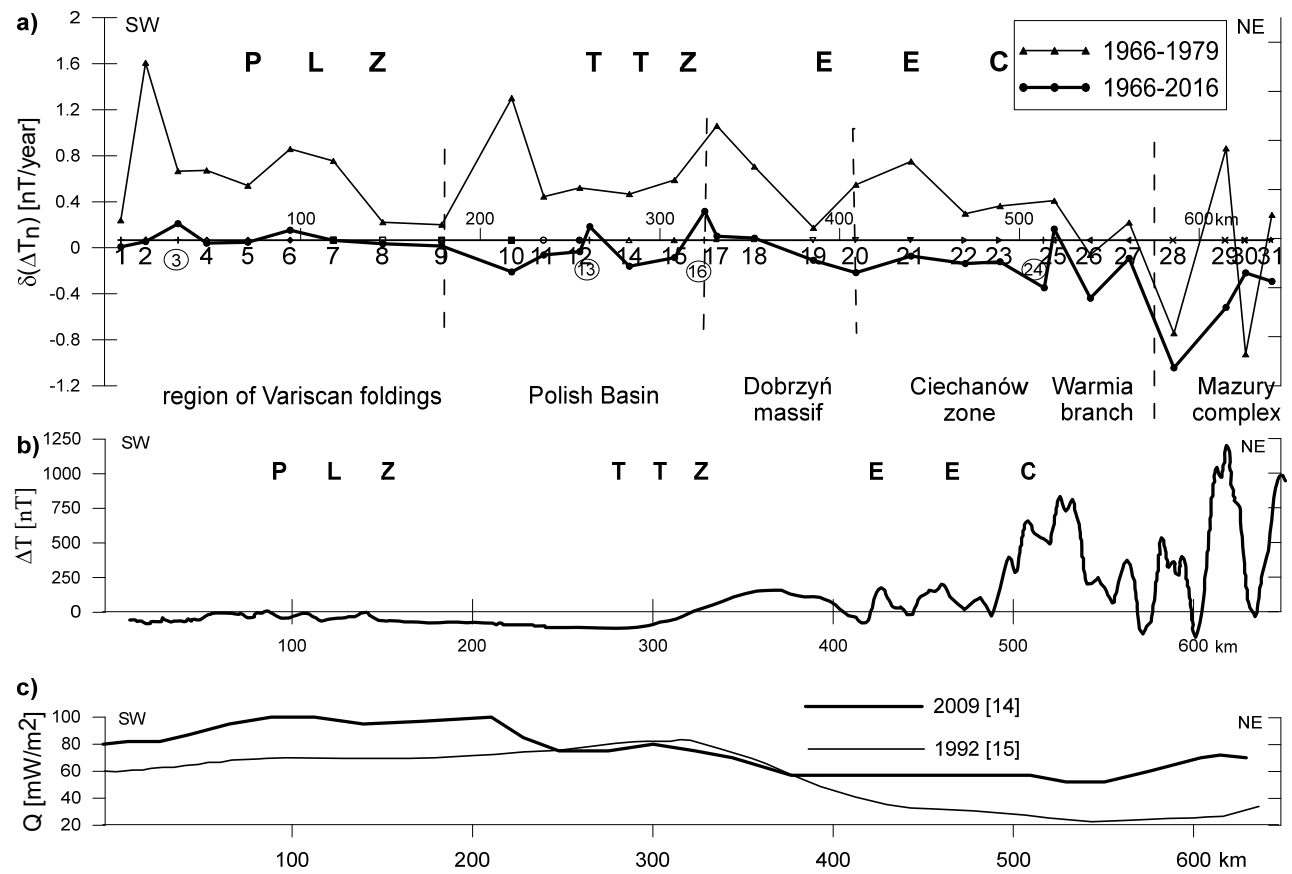

Fig. 3. Comparison of relative secular variations of the geomagnetic field $\delta(\Delta T n)$ (a), magnetic anomalies $\Delta T$ (b) and terrestrial heat flow density $Q$ (c). Explanations (3a): numbers in circles are sites where the measurements are not conducted nowadays (industrial noise), vertical dotted line division into sections with different rates of change 
Figure 3a presents the relative secular variations of the geomagnetic field in the two time intervals, i.e. 1966-1979 and 1966-2016 (13 and 50 measurement series, respectively). The curves obtained show trends of changes in relation to the geomagnetic field recorded in the Belsk Observatory, in the PLZ and EEC areas. The graph of the relative secular variations along the Z-W profile was compiled with the observed magnetic anomalies $(\Delta T)$ (Fig. 3b) as well as changes of the terrestrial heat flow density $(Q)$ (Fig. 3c).

\section{Discussion}

In the years 1980-1990 and 2000-2005 (grey background in Fig. 2) systematic changes of the geomagnetic field were observed in Central Europe [5]. However, the years 1990-2000 were considered to be a period of disturbances in the regularity of field changes. Comparing the results of the relative values of the geomagnetic field during these three time periods in each secular point, the similar to established by E. Welker's character of field changes was noted in the few secular points of the Z-W profile. This means that probably irregular changes of the geomagnetic field, which were observed in Central Europe in the years 1990-2000, did not affect the results of the survey along the Z-W profile.

It is also interesting to note that since 2000 slight relative secular variations of the geomagnetic field are observed along the Z-W profile (Fig. 2). At the beginning of this period a lesser rate of field changes dynamics was noted by Welker [5], who defined this period as a time of return to regular changes (2000-2005). It should be emphasised that the decrease in the dynamics of field changes along the Z-W profile since 2000 caused the decrease of the bn coefficient, corresponding to relative secular variations (Fig. 2).

The analysis of relative secular variations for 13 (1966-1979) and 50 (1966-2016) measurement series (Fig. 3a) along the Z-W profile, highlights the similarity of two curves. For example, in the region at the boundary of the Polish Basin and Dobrzyń massif, the increase of relative secular variations (bn coefficient) for both curves is in agreement.

The adopted methodology of data processing and a long time of the geomagnetic field observations allow us to relate the relative secular variations of the geomagnetic field to the phenomena occurring in the Earth's crust and upper mantle as well as their different physicochemical properties affecting the transmission of the slowly changing geomagnetic field generated in the outer core. The causes of secular variations can be displacements of magnetic bodies during tectonic movements (tectonomagnetic phenomena), earthquakes (seismomagnetic effects), thermal, elastic or chemical interactions associated with changes in rocks magnetization or electrical conductivity changes (telluric currents). Time changes of the geomagnetic field may also involve a change of the induced magnetization of rocks in the Earth's crust as a result of changes of the normal geomagnetic field.

The character of relative secular variations along the Z-W profile shows a lower rate of changes (relative to the Belsk Observatory) of relative secular variations in the EEC area in comparison with the PLZ (Fig. 3a). This phenomenon was found earlier [10] and its relationship to the processes occurring in the upper mantle is not excluded. The slowdown in the increase of geomagnetic field in the EEC area (up to c. $-1.0 \mathrm{nT} /$ year) is especially well visible in the region of rapakivi-like granitoids and the Suwałki anorthosite massif (strong magnetic anomalies, Fig. 3b). The other part of the Z-W profile, including the area of the PLZ, is characterized by temporal dynamics of relative secular variations decreasing in time, a quiet magnetic anomalies pattern and the increasing values of terrestrial heat flow density (Fig. 3c).

In Figure 3c, the terrestrial heat flow density along the Z-W profile is presented. The variation of this parameter defines a hot province over the PLZ and TTZ, and the cold domain corresponding to the EEC, the characteristics providing important, additional information to the study of relative secular variations of the geomagnetic field. The lower terrestrial heat flow density in the EEC associated with a larger thickness of the crystalline crust indicates 
slower heat conduction from the mantle, which may affect the recorded geomagnetic field and cause the observed slower relative secular variations in the EEC area.

\section{Conclusions}

The results of observations carried out for the last 50 years along the Zgorzelec-Wiżajny profile support the following conclusions:

1. The character and dynamics of the relative secular variations of the TMI of the geomagnetic field along the Z-W profile correspond to the geological division of the studied area.

2. The observations of the relative secular variations of the geomagnetic field are important in the study of the Earth's crust, especially in places where highly magnetic rocks are present. The observations may also be affected by processes occurring in the crust-upper mantle interface.

3. The EEC area is characterized by a slower rate of the geomagnetic field changes, compared to the field recorded at the Central Geophysical Observatory in Belsk. The relative secular variations in this region during the last 50 years of study amount to c. $-1.0 \mathrm{nT} /$ year. Sources of the relative secular variations in the EEC are still not recognized.

4. In the area of the Palaeozoic Platform of Central and Western Europe, the higher rate of the geomagnetic field changes is observed. It should be noted that the results of measurements in this region are closer to the value of the geomagnetic field recorded in the Belsk Observatory.

5. Long-term studies show that since 2000 the relative secular variations of the geomagnetic field along the Zgorzelec-Wiżajny profile were low. They may correspond to the regular secular variations observed in Central Europe in this time.

\section{Acknowledgements}

The studies were carried out by the Department of Geophysics, statutory research of the Faculty of Geology, Geophysics and Environmental Protection, AGH-UST, grant no 11.11.140.768. The results presented in this paper rely, among others, on the data collected at the Belsk Observatory. We thank the Polish Academy of Sciences, for supporting its operation and INTERMAGNET for promoting high standards of magnetic observatory practice (www.intermagnet.org).

\section{Referencess}

1. A. Uhrynowski, Works of the Institute of Geodesy and Cartography 24, 2, 3-32 (1977a)

2. A. Uhrynowski, Works of the Institute of Geodesy and Cartography 24, 3 (1977b)

3. A. Uhrynowski, Works of the Institute of Geodesy and Cartography 39, 1, 87 (1992)

4. E. Welker, A.M. Żółtowski, Works of the Institute of Geodesy and Cartography 40, 1, 88, 103-118 (1993)

5. E. Welker, Works of the Institute of Geodesy and Cartography 53, 111 (2007)

6. S. Małoszewski, Scientific Papers of the University of Mining and Metallurgy (AGH) 44 (1965)

7. G. Bojdys, T. Grabowska, Acta Geophys. 55, 2, 169-181 (2007)

8. N. Narkiewicz, A. Maksym, M. Malinowski, M. Grad, A. Guterch, Z. Petecki, J. Probulski, T. Janik, M. Majdański, P. Środa, W. Czuba, E. Gaczyński, L. Jankowski, Int. J. of Earth Sciences 104, 775-796 (2015)

9. R. Dadlez, Z. Kowalczewski, J. Znosko, Kwart. Geol. 38, 2, 169-190 (1994) 
10. S. Małoszewski, J. Jankowski, Acta Geophys. Pol. 45, 23-31 (1997)

11. R. Dadlez, Mapa tektoniczna kompleksu cechsztyńsko-mezozoicznego na Niżu Polskim, $1: 500$ 000. PGI-NRI (1998)

12. M. Wilde-Piórko, M. Swieczak, M. Grad, M. Majdański, Tectonophysics 481, 108-115 (2010)

13. A. Koblański, Scientific Papers of the University of Mining and Metallurgy (AGH) 5, 92-93 (1989)

14. J. Szewczyk, D. Gientka, Geol. Quart., 53, 1, 125-140 (2009)

15. M. Plewa, S. Plewa, D. Poprawa, A. Tomas, Geothermal Atlas of Europe (1992) 